\title{
Preclinical Brown Norway Rat Models for the Assessment of Infant Formulas in the Prevention and Treatment of Cow's Milk Allergy
}

\author{
Jensen, Louise Heydenreich; Larsen, Jeppe Madura; Madsen, Charlotte Bernhard; Laursen, R. R.; \\ Jacobsen, Lotte Neergaard; Bøgh, Katrine Lindholm
}

Published in:

International Archives of Allergy and Immunology

Link to article, DOI:

$10.1159 / 000495801$

Publication date:

2019

Document Version

Peer reviewed version

Link back to DTU Orbit

Citation (APA):

Jensen, L. H., Larsen, J. M., Madsen, C. B., Laursen, R. R., Jacobsen, L. N., \& Bøgh, K. L. (2019). Preclinical Brown Norway Rat Models for the Assessment of Infant Formulas in the Prevention and Treatment of Cow's Milk Allergy. International Archives of Allergy and Immunology, 178(4), 307-314. https://doi.org/10.1159/000495801

\section{General rights}

Copyright and moral rights for the publications made accessible in the public portal are retained by the authors and/or other copyright owners and it is a condition of accessing publications that users recognise and abide by the legal requirements associated with these rights.

- Users may download and print one copy of any publication from the public portal for the purpose of private study or research.

- You may not further distribute the material or use it for any profit-making activity or commercial gain

- You may freely distribute the URL identifying the publication in the public portal 
1

\title{
Preclinical Brown Norway rat models for the assessment of infant formulas in the prevention and treatment of cow's milk allergy
}

\author{
Louise Heydenreich Jensen ${ }^{1, a, c}$, Jeppe Madura Larsen ${ }^{1, c}$, Charlotte Bernhard Madsen ${ }^{1}$, Rune \\ Rønhave Laursen ${ }^{2, b}$, Lotte Neergaard Jacobsen ${ }^{3}$, Katrine Lindholm Bøgh ${ }^{1}$
}

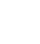

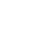

(1)

\footnotetext{
${ }^{1}$ National Food Institute, Technical University of Denmark, Lyngby, Denmark.

${ }^{2}$ Research \& Development, Arla Foods Ingredients Group P/S, Videbæk, Denmark ${ }^{3}$ Strategic Business Unit Pediatric, Arla Foods Ingredients Group P/S, Viby J, Denmark ${ }^{a}$ Current workplace: HERAX, Hørsholm, Denmark ${ }^{b}$ Current workplace: DuPont Nutrition \& Health, Aarhus, Denmark ${ }^{\mathrm{c} C o-f i r s t}$ author
} 8 9 20 Short Running Title: Milk allergy prevention and treatment by infant formulas (1) 3 Keywords: Food allergy, animal models, milk, infant formula. 5 6

7 Corresponding Author: Katrine Lindholm Bøgh, National Food Institute, Technical University of 8 Denmark, DK-2800 Kgs. Lyngby, Denmark. E-mail: kalb@food.dtu.dk. Phone: +45 3588 7092, Fax: +453588 7001 . 
30

31

32

33

34

35

36

37

38

39

40

41

42

43

44

45

46

47

48

49

50

51

52

53

54

55

56

57

58

Abstract

\section{Background}

Infant formulas (IFs) based on hydrolysed cow's milk proteins are central in the management of cow's milk allergy (CMA) in infants and small children. New IF compositions with improved prevention and treatment properties are needed along with appropriate preclinical animal models to evaluate these properties before introduction into humans.

\section{Objectives}

Develop preclinical models for the assessment of the primary preventive and desensitising capacity of cow's milk IF in allergy prone high IgE-responder Brown Norway rats.

\section{Method}

Preventive capacity was assessed in cow's milk naïve rats given a 2 or 4-week regimen of wheybased extensively hydrolysed IF (eHF), partially hydrolysed IF (pHF), or intact beta-lactoglobulin (BLG) ad libitum in drinking bottles followed by intraperitoneal (IP) immunisation with BLG. Desensitising capacity was assessed in orally BLG-sensitised rats after a 3 or 6-week regimen of eHF, pHF, or intact BLG administration in drinking bottles followed by IP challenges with BLG. Primary preventive and desensitising capacity were analysed by serum BLG-specific IgG1 and IgE.

\section{Results}

The preventive regimens did not induce detectable BLG-specific IgG1 or IgE in cow's milk naïve rats. A preventive regimen consisting of $\mathrm{pHF}$ or $\mathrm{BLG}$, but not eHF, induced complete tolerance to BLG, as demonstrated by the absence of BLG-specific IgE following IP immunisation. Desensitising regimens had a limited effect on BLG-specific IgG1 or IgE when comparing before and after treatment in sensitised rats. IP challenge with BLG increased BLG-specific IgE in all treatment regimens except for the BLG group, suggesting a limited desensitising capacity of IF based on hydrolysates and a need for the presence of intact allergen for desensitisation.

\section{Conclusions}

The presented models highlight that different mechanisms are at play in the induction of de novo tolerance to cow's milk proteins and in the desensitisation of CMA. Different IF products may be needed for primary prevention and treatment of CMA. 


\section{INTRODUCTION}

Cow's milk allergy (CMA) is one of the most common IgE-mediated food allergies in infancy and early childhood. It affects proximately $2-3 \%$ of infants [1,2], but the majority of afflicted infants outgrow the disease during childhood [3]. In general, the only way of managing food allergy is strict avoidance of the offending food. However, for infants with CMA or infants at the risk of getting CMA, alternatives exist as cow's milk based hypoallergenic infant formulas (IFs) are available when breastfeeding is not possible or sufficient.

Hypoallergenic IFs have a lower allergenic potential compared to standard IF as the protein fraction has been hydrolysed leading to destruction of allergenic epitopes. Based on the degree of hydrolysis and the peptide distribution, the hypoallergenic IF can be classified as either extensively hydrolysed formula (eHF) or partially hydrolysed formula (pHF) [4]. The eHFs are recommended for management of allergy in infants with a diagnosed CMA due to the low allergenicity of these formulas and thus reduced risk of elicitation of symptoms [4,5]. On the other hand, pHFs are recommended for infants at the risk of developing CMA, since it is believed that the larger peptides can be recognised by the immune system giving rise to tolerance development in the absence of intact allergen [6]. Clinical studies indicate that both eHF and pHF may have primary preventive capacity [5,7-10]. However, the evidence is not strong [11]. It is unclear which biochemical and biophysical properties are important for a tolerogenic effect of a hypoallergenic IF are unclear, although it has been suggested that the degree of hydrolysis (DH) is not the only contributing factor [12]. Furthermore, oral immunotherapy is emerging as a viable treatment option of food allergy $[13,14]$. Thus, it would be of clinical interest if IFs could be developed to include a desensitising capacity for the treatment of CMA.

In summary, improved IFs with documented primary preventive and desensitising capacity are needed for the management of CMA in infants and young children. Development of new IFs calls for better animal models in the assessment of different formula compositions in terms of $\mathrm{DH}$, peptide distribution, biochemical, biophysical and immunological properties. Recent changes in the EU regulation of IFs require health claims to be clinically documented, which include completion of human trials. This requirement further highlights the need for appropriate preclinical models in the selection of formula compositions for testing in humans. Here we present models for assessment of primary preventive and desensitising capacity of IF in allergy prone high 
89 IgE-responder Brown Norway (BN) rats [15] mimicking atopic predisposition in humans. We

90 compared the primary preventive and desensitising capacity of whey-based eHF and pHF to intact

91 beta-lactoglobulin (BLG), the main food allergen in whey. The presented models can be used to

92 assess the degree of tolerance induced by different formulas, as well as the capacity to induce

93 desensitisation. Interestingly, our results indicate that intact protein should be present in IFs to

94 obtain desensitising capacity.

95

96

97 


\section{MATERIALS AND METHODS}

\section{Cow's milk protein products}

Arla Foods Ingredients (Videbæk, Denmark) kindly provided the cow's milk protein products used for the development of animal models. The products included: 1) Peptigen ${ }^{\circledast}$ IF-3080 (eHF) - an extensively hydrolysed whey protein product suitable for use in hypoallergenic IF with a DH of 27 (peptide distribution: <375 Da (1-3 AA): 16,6 \%, 375-750 Da (4-6 AA): 38,7 \%, 750-1250 Da (7-10 AA): 26 \%, 1250-2500 Da (11-20 AA): 15,8\%, >2500 Da (>20 AA): 3 \%). 2) Peptigen ${ }^{\circledR}$ IF3087 (pHF) - a partially hydrolysed whey protein suitable for use in infant formulas with reduced allergen content with a DH of 18,3 (peptide distribution: <375 Da (1-3 AA): 15,4 \%, 375-750 Da (46 AA): $26,6 \%, 750-1250$ Da (7-10 AA): 22,1 \%, 1250-2500 Da (11-20 AA): 23,9 \%, >2500 Da (>20 AA): $12 \%) .3$ ) Purified intact BLG (> 90\% purity).

\section{Animal experiments}

BN rats were bred and raised in-house at the National Food Institute, Technical University of Denmark, and kept on a special diet free from cow's milk proteins for a minimum of 3 generations to avoid tolerance to cow's milk proteins. Rats were housed in macrolon cages at $22 \pm$ $1{ }^{\circ} \mathrm{C}$ and $55 \pm 5 \%$ relative humidity with a $12 \mathrm{~h}$ light-dark cycle. Studies were approved by the Danish Animal Experiments Inspectorate (authorisation number 2015-15-0201-00553-C1). The experiments were overseen by the National Food Institutes in-house Animal Welfare Committee for animal care and use. Liquid consumption was monitored daily in cages each containing three animals, and calculated as the total consumption pr. animal each week.

\section{Primary prevention model}

Primary prevention of CMA was induced by ad libitum administration of cow's milk protein products in rat drinking bottles for 2 or 4 weeks starting at 3-5 weeks of age. The cow's milk protein product concentration was comparable to commercial IF $(12.5 \mathrm{~g} / \mathrm{L})$ and dissolved in Milli-Q (Millipore Corporation, USA) purified water. The degree of induced tolerance was assessed one week later by 3 IP immunisations with $100 \mu \mathrm{g}$ BLG/rat without adjuvant at one-week intervals. Blood was collected one week after the primary prevention regimen and after each IP injections for the assessment of BLG-specific IgG1 and IgE in serum (Figure 1A). 
128

129

130

131

132

133

134

135

136

137

138

139

140

141

142

143

144

145

146

147

148

149

150

151

152

153

154

155

156

157

158

\section{Desensitisation model}

Rats were sensitised to cow's milk by daily oral gavage of $10 \mathrm{mg}$ BLG with $2 \mu \mathrm{g}$ cholera toxin (CT; Sigma) for 6 weeks starting at 3-5 weeks of age. One week later, desensitisation was induced by ad libitum administration of cow's milk protein products in rat drinking bottles for 3 to 6 weeks. The milk protein product concentration was comparable to commercial IF ( $12.5 \mathrm{~g} / \mathrm{L})$ and dissolved in Milli-Q purified water. Only rats with measurable BLG-specific IgE before treatment were included in the analysis of the desensitisation regimen effect. The degree of desensitisation was assessed one week later by 3 IP challenges with $50 \mu \mathrm{g}$ BLG/rat at one-week intervals. Blood was collected after sensitisation, after desensitisation, and a week after the third IP challenge for assessment of BLG-specific IgG1 and IgE in serum (Figure 2A).

\section{BLG-specific IgG1 and IgE assays}

BLG-specific IgG1 antibodies were measured in serum using in-house developed indirect ELISAs. Maxisorp plates (96-well, NUNC, Roskilde, Denmark) were coated with $100 \mu \mathrm{L} /$ well of $10 \mu \mathrm{g} / \mathrm{mL}$ intact or denatured BLG in carbonate buffer ( $15 \mathrm{mM} \mathrm{Na}_{2} \mathrm{CO}_{3}, 35 \mathrm{mM} \mathrm{NaHCO}_{3} ; \mathrm{pH}$ 9.6) over night at $4^{\circ} \mathrm{C}$. Following, plates were incubated for $1 \mathrm{~h}$ at room temperature (RT) with 50 $\mu \mathrm{L} /$ well of 2-fold serial diluted rat serum samples in PBS-T (PBS (137 mM NaCl, $3 \mathrm{mM} \mathrm{KCl}, 8 \mathrm{mM}$ $\mathrm{Na}_{2} \mathrm{HPO}_{4}, 1 \mathrm{mM} \mathrm{KH} \mathrm{PO}_{4} ; \mathrm{pH}$ 7.2) with 0.01\% (w/v) Tween 20 (P1379, Sigma)) starting at 1:8 dilution. Subsequently, the plates were incubated for $1 \mathrm{~h}$ with $50 \mu \mathrm{L} /$ well of $20.000 \mathrm{x}$ diluted horseradish peroxidase (HRP)-labelled mouse-anti-rat-IgG1 (3060-05, Southern Biotech, Birmingham, AL, USA).

BLG-specific IgE antibodies were measured in serum using in-house developed IgE capture ELISAs. Maxisorp 96-well plates were coated with $100 \mu \mathrm{L} /$ well of $0.5 \mu \mathrm{g} / \mathrm{mL}$ mouse-antirat-IgE (HDMAB-123, Patricell LTD, Nottingham, United Kingdom) in carbonate buffer over night at $4^{\circ} \mathrm{C}$. Plates were blocked for $1 \mathrm{~h}$ at $37^{\circ} \mathrm{C}$ with $200 \mu \mathrm{L} /$ well PBS-T containing $5 \%$ horse serum (v/v; S0900-500, Biowest, France). Subsequently, plates were incubated for $1 \mathrm{~h}$ at RT with $50 \mu \mathrm{L} /$ well of 2-fold serial diluted rat serum samples in PBS-T starting at 1:8 dilution. The plates were incubated for $1 \mathrm{~h}$ at RT with $50 \mu \mathrm{L} /$ well of $0.05 \mu \mathrm{g} / \mathrm{mL}$ digoxigenin (DIG)-coupled BLG (coupling 10:1) in 5\% horse serum (v/v) followed by incubation with $50 \mu \mathrm{L} /$ well of $1.000 x$ diluted anti-DIG (11633716001, Roche GmbH, Mannheim, Germany) in 5\% horse serum for $1 \mathrm{~h}$. 
159

160

161

162

163

164

165

166

167

168

169

170

171

172

173

174

175

176

177

178

179

180

Both assays included washing of plates 5 times with (PBS-T) between each step.

Plates were developed by incubating with $100 \mu \mathrm{L} /$ well of 3,3',5,5'-tetramethylbenzidine (TMB)-

one (4380A, Kementec Diagnostics, Taastrup, Denmark) for $12 \mathrm{~min}$ and stopping the reaction with $100 \mu \mathrm{L} /$ well of $0.2 \mathrm{M} \mathrm{H}_{2} \mathrm{SO}_{4}$. The absorbance was measured at $450 \mathrm{~nm}-630 \mathrm{~nm}$. The results were expressed as $\log _{2}$ titre values with a cut-off value set higher than the mean absorbance for the negative control + three times the standard deviation. Each plate included positive and negative control samples for quality control of day-to-day and plate-to-plate variation.

\section{Denaturation of BLG}

BLG was denatured by reduction and alkylation as previously described [16].

\section{Statistics}

Differences between water control group and prevention regimen groups were tested using Kruskal-Wallis test with Dunn's correction for multiple testing at each sampling time point. Differences between paired data were tested using Wilcoxon matched-pairs signed-rank test. Differences in liquid consumption and desensitisation post-challenge Ig levels between water control group and regimen groups were tested using ANOVA with Bunnett's correction for multiple testing. All statistical analyses were performed in GraphPad Prism 7.04 for MS Windows. P-values below 0.05 were considered statistically significant. Significance levels were indicated as ${ }^{*} p<0.05, * * p<0.01$, and $* * * p<0.001$ in figures. 
181

182

183

184

185

186

187

188

189

190

191

192

193

194

195

196

197

198

199

200

201

202

203

204

205

206

207

208

209

210

\section{RESULTS}

\section{Model for primary prevention of cow's milk allergy}

We developed a model in $\mathrm{BN}$ rats for the assessment of primary prevention against milk allergy by cow's milk whey-based IFs. The model included a prevention regimen with ad libitum oral administration of IF in drinking bottles followed by IP immunisation with BLG to assess the degree of established tolerance (Figure $1 \mathrm{~A}$ ). This model was based on pilot investigations performed to optimise milk protein concentrations, number of IP immunisations, BLG IP concentration, the use of adjuvant, and rat age and sex (data not shown). It was decided that the protein concentration of the administered hydrolysates should be equivalent to commercial IFs $(12.5 \mathrm{~g} / \mathrm{L})$. Since there were no significant differences between a 2 and 4 week primary prevention regimen, the results shown combined data from experiments using both regimens (Figure 1B-D).

The prevention regimen alone did not induce native $B L G$-specific $\lg G 1$ or $\lg E$ in rats receiving only water, eHF, pHF, or intact BLG in the drinking bottles (Figure 1B-C). IP immunisations with BLG induced increasing native BLG-specific IgG1 and IgE levels in rats not receiving an active preventive regimen (water alone), demonstrating that IP administration induced BLG sensitisation. Rats receiving a prevention regimen containing $\mathrm{pHF}$ or BLG, but not eHF, were found to have significantly reduced serum native BLG-specific IgG1. The induction of native BLG-specific IgE was largely undetectable after pHF or BLG prevention regimens, indicating that these regiments induce complete tolerance to milk proteins. Only rats having received a preventive regimen containing eHF had a significantly lower levels of IgG1 specific for denatured compared to native BLG (Figure 1D).

Liquid consumption was similar in all prevention groups (Figure $1 \mathrm{E}$ ), indicating that the differences in preventive capacity between milk protein products cannot be ascribed to differences in consumed dosages.

\section{Model for desensitisation in cow's milk allergy}

We developed a model in BN rats to assess the desensitising effect of cow's milk whey-based infant formulas. The model used orally BLG-sensitised rats receiving a desensitisation regimen with ad libitum oral administration of IF in drinking bottles followed by IP challenges with BLG (Figure 2A). This model was based on pilot investigations performed to optimise oral 
211 sensitisation, the use of adjuvant, BLG IP concentration, number of challenges, and rat age and sex

212 (data not shown). Since there were no significant differences between a 3 and 6 week

213 desensitisation regimen, the results shown combined data from experiments using both regimens

214 (Figure 2B-G). Only rats with measurable native BLG-specific IgE before treatment were included in

215 the analysis of the desensitisation regimen (Figure 2B-G).

216 The desensitisation regimens using eHF, pHF, or intact BLG were found to have a

217 limited effect on native BLG-specific IgG1 and IgE levels when comparing before and after

218 treatment (Figure 2B-C). Only the BLG desensitisation regimen was found to significantly increase

219 native BLG-specific IgG1 in serum. However, IP challenges with BLG significantly increased native

220 BLG-specific IgG1 and IgE in rats having received a desensitisation regimen containing water only,

221 eHF or pHF, but not BLG (Figure 2D-E). Furthermore, the post-challenge native BLG-specific IgG1

222 and IgE levels were significantly lower in rats having received the BLG desensitisation regimen

223 (Figure $2 \mathrm{~F}-\mathrm{G}$ ). These findings suggest that desensitisation requires the presence of intact protein

224 and cannot be mediated by hydrolysed products. Liquid consumption was similar in all

225 desensitisation groups (data not shown) indicating that findings cannot be ascribed to differences

226 in consumed dosages. 
231

232

233

234

235

236

237

238

239

240

241

242

243

244

245

246

247

248

249

250

251

252

253

254

255

256

257

258

259

260

\section{DISCUSSION}

Reduced allergenicity of cow's milk proteins in IFs is important when administered to infants with an established CMA. This property can readily be assessed by in vitro assay using materials from allergic humans or sensitised animals [17]. However, it is also of interest to assess a potential tolerogenic capacity of IF for the primary prevention and treatment of CMA. This assessment requires appropriate animal models [14] that can be experimentally sensitised before and after the administration of IF. Such models would be particularly useful for the preclinical screening of new IF product candidates before trials in humans, which is required by recent EU regulation of IF products to allow labelling of health claims. We have previously assessed the allergenicity of hydrolysed IFs in high IgE-responder BN rats, which reflect the findings from other studies in animals and humans $[16,18]$. Here we developed two new models using this allergy prone rat strain for the assessment of primary preventive and desensitising capacity of wheybased hydrolysed IF.

The $\mathrm{BN}$ rats used for these experiments were kept on a milk-free diet for more than 3 generations to ensure complete immunological naivety to cow's milk proteins. Administration of eHF, pHF, or intact BLG for the prevention of CMA was not associated with the development of native BLG-specific IgG1 or IgE, suggesting absence of humoral immune responses to the orally administered proteins. Next, we immunised the animals by IP injections of BLG to assess the degree of established tolerance by the IF. The level of sensitisation increased with increasing numbers of IP immunisations with BLG in rats not having received an active preventive regimen. pHF and BLG induced complete tolerance to BLG, whereas eHF did not. This finding is in line with the assumption that larger peptides are required for IFs to have preventive capacity, likely due to higher immunogenicity of pHF compared to eHF [6]. The mechanisms by which the oral preventive regimens induce tolerance to BLG cannot be determined based on our data, however the absence of native BLG-specific IgG1 before IP immunisations suggest exclusion of tolerance mediated by IgG [19]. Rather the mechanism may involve generation of BLG-specific regulatory $T$ cells, as suggested by a previous study using preventive administration of specific peptides derived from BLG [20].

sensitised to BLG. The 3 to 6-week oral desensitisation regimen of eHF, pHF, or intact BLG had no 
261 effect on the level of native BLG-specific IgE antibodies when comparing levels before and after 262 treatment. However, IP challenges with BLG significantly increased the level of native BLG-specific 263 IgE in rats with a desensitisation regimen consisting of water alone, eHF, or pHF, but not with BLG, 264 leading to higher post-challenge native BLG-specific IgE levels in all regimen groups compared to 265 the BLG regimen. Thus, the hydrolysed IFs had a limited desensitisation capacity, whereas the 266 intact BLG regimen prevented further sensitisation. This indicates that the presence of intact 267 protein is required for desensitisation. Interestingly, we previously found that the sensitising 268 capacity of intact BLG was reduced by co-administration with digested BLG [21], yet the desensitising capacity of such a mixture remains unknown. Previous studies have reported a desensitising capacity of pepsin-hydrolysed cashew nut protein extract [22] and aminopeptidasehydrolysed egg white [23], however the presence of intact protein in these preparations is unclear.

272 Several studies have demonstrated a therapeutic effect of T cell-directed peptide epitopes from 273 ovalbumin [24], ovomucoid [25], tropomyosin [26], and BLG [27] in sensitised mice. These studies 274 support the concept of a desensitising capacity of hydrolysates and specific peptides. The lack of desensitising capacity of eHF and pHF reported here could be attributed to the specific composition of the hydrolysed IFs, including the absence of T cell epitopes, specific biochemical/biophysical properties, or differences between the specific food allergens. Interestingly, recent clinical trials using Fel d 1 peptide therapy found no therapeutic effect, suggesting that this approach has limited applicability in humans (Circassia Pharmaceuticals plc, 20 June 2016 press release, www.circassia.com). Thus, it may be important that future therapeutic agents and IFs in part contain intact allergens, possibly to ensure immunemodulation of conformational epitopes.

Overall, our findings are in line with emerging clinical data on the prevention and treatment of food allergy. The LEAP study has recent shown, that early introduction of peanut prevent the development of peanut allergy in high-risk infants [28]. Still, high-quality clinical studies are needed on pHF in the prevention of CMA [29]. Oral immunotherapy is emerging as a viable treatment option for food allergy [13], but issues concerning efficacy and adverse effects remain central obstacles, which novel preclinical models may contribute to solving. desensitisation capacity of IF, highlight that different mechanisms are at play in the induction of 
291 tolerance to cow's milk proteins and the desensitisation in CMA. This indicates that different IF

292 products have to be developed for the primary prevention and treatment of CMA, respectively.

293

294

295

296

297

298 
299

300

301

302

303

304

305

306

307

308

309

310

311

312

313

314

315

316

317

318

319

320

321

322

323

324

\section{Figure text}

Figure 1 - Assessment of primary preventive capacity of whey-based hydrolysed infant formula (IF): Model design with 2 or 4 weeks of administration with whey-based extensively hydrolysed IF (eHF, $n=12$ ), partially hydrolysed IF ( $p H F, n=12)$, intact beta-lactoglobulin $(B L G, n=$ 12), or water alone (water, $n=6$ ) ad libitum in drinking bottles to cow's milk naïve Brown Norway rats followed by three IP immunisations with BLG without adjuvant ( $A$; photo/illustration credit: Colourbox.com). Native BLG-specific IgG1 (B) and IgE (C) one week after the prevention regimen and each of the IP immunisations (median with upper IQR, and Kruskal-Wallis test with Dunn's correction for multiple testing). Levels of specific $\operatorname{lgG} 1$ to native compared to denatured BLG one week after third IP immunisation (D; Wilcoxon matched-pairs signed-rank test). Liquid consumption by rats during the preventive regimen (E; $n=8$ (water group; 2 cages observed for 4 week), $\mathrm{n}=12$ (eHF, pHF and BLG groups; 2 cages observed for 2 week and 2 cages observed for 4 weeks), mean with SEM, and ANOVA test with Bunnett's correction for multiple testing).

Figure 2 - Assessment of desensitising capacity of whey-based hydrolysed infant formula (IF): Model design with oral BLG-sensitisation of Brown Norway rats followed by 3 to 6weeks of administration with whey-based extensively hydrolysed IF (eHF, $n=7$ ), partially hydrolysed IF ( $\mathrm{pHF}, \mathrm{n}=10$ ), intact beta-lactoglobulin (BLG, $n=8)$, or water alone (water, $n=11$ ) ad libitum in drinking bottles, and three IP challenges with BLG (A; photo/illustration credit: Colourbox.com). BLG-specific $\lg G 1$ (B) and $\lg E$ (C) before and after the desensitisation regimen (Wilcoxon matched-pairs signed-rank test). BLG-specific IgG1 (D) and IgE (E) before and after three IP challenges with BLG (Wilcoxon matched-pairs signed-rank test). Comparison of BLG-specific $\lg G 1(F)$ and $\operatorname{lgE}(\mathrm{G})$ levels between regimen groups after three IP challenges with BLG (mean with SEM, and ANOVA test with Bunnett's correction for multiple testing). 
52

\section{Acknowledgement}

The authors thank animal technician Eva Ferdinansen, Elise Navntoft, Maja Danielsen and Anne Ørngreen, and laboratory technician Lene Hansen for their excellent assistance and support.

\section{Statement of Ethics}

All animal experiments were conducted in accordance to internationally accepted standards, and have been approved by the Danish Animal Experiments Inspectorate.

\section{Disclosure Statement}

KLB has ongoing collaboration with the company Arla Foods Ingredients $\mathrm{P} / \mathrm{S}$, which supplied the whey-based IF products for this study. Arla Foods Ingredients $\mathrm{P} / \mathrm{S}$ provided financial support for past and ongoing research projects. The authors have no other conflicts of interest to declare.

\section{Funding Sources}

Funding from The Danish Dairy Research Foundation is highly acknowledged. The funding bodies had no role in study design; in the collection, analysis, and interpretation of data; in the writing of the manuscript; and in the decision to submit the manuscript for publication.

\section{Author Contributions}

KLB and CBM conceived the study and designed experiments. LHJ performed experiments and collected the data. KLB, JML, and LHJ analysed and interpreted the data. JML and LHJ wrote the manuscript. RRL and LNJ supplied and characterised BLG and whey-based IF products. All authors provided important intellectual contributions to the study and reviewing of the manuscript. 
354

355

356

357

358

359

360

361

362

363

364

365

366

367

368

369

370

371

372

373

374

375

376

377

378

379

380

381

382

383

\section{References}

1. Høst A. Frequency of cow's milk allergy in childhood. Ann Allergy Asthma Immunol 2002;89:33-37.

2. Sampson HA. Update on food allergy ir. J Allergy Clin Immunol 2004;113:805-819.

3. Skripak JM, Matsui EC, Mudd K, Wood RA. The natural history of IgE-mediated cow's milk allergy. J Allergy Clin Immunol 2007;120:1172-1177.

4. Høst A, Koletzko B, Dreborg S, Muraro A, Wahn U, Aggett $P$ et al. Dietary products used in infants for treatment and prevention of food allergy. Joint Statement of the European Society for Paediatric Allergology and Clinical Immunology (ESPACI) Committee on Hypoallergenic Formulas and the European Society for Paediatric Gastroenterology, Hepatology and Nutrition (ESPGHAN) Committee on Nutrition. Arch Dis Child 1999;81:8084.

5. Bahna SL. Hypoallergenic formulas: optimal choices for treatment versus prevention. Ann Allergy Asthma Immunol 2008;101:453-9; quiz 459-61, 481.

6. Crittenden RG, Bennett LE. Cow's milk allergy: a complex disorder. J Am Coll Nutr 2005;24:582S-91S.

7. Vandenplas Y, Hauser B, Van den Borre C, Clybouw C, Mahler T, Hachimi-Idrissi S et al. The long-term effect of a partial whey hydrolysate formula on the prophylaxis of atopic disease. Eur J Pediatr 1995;154:488-494.

8. Oldaeus G, Anjou K, Björkstén B, Moran JR, Kjellman NI. Extensively and partially hydrolysed infant formulas for allergy prophylaxis. Arch Dis Child 1997;77:4-10.

9. Halken S, Hansen KS, Jacobsen HP, Estmann A, Faelling AE, Hansen LG et al. Comparison of a partially hydrolyzed infant formula with two extensively hydrolyzed formulas for allergy prevention: a prospective, randomized study. Pediatr Allergy Immunol 2000;11:149-161.

10. Nentwich I, Michková E, Nevoral J, Urbanek R, Szépfalusi Z. Cow's milk-specific cellular and humoral immune responses and atopy skin symptoms in infants from atopic families fed a partially (pHF) or extensively (eHF) hydrolyzed infant formula. Allergy 2001;56:1144-1156.

11. Nieto A, Wahn U, Bufe A, Eigenmann P, Halken S, Hedlin G et al. Allergy and asthma prevention 2014. Pediatr Allergy Immunol 2014;25:516-533.

12. Meulenbroek LAPM, Oliveira S, den Hartog Jager CF, Klemans RJB, Lebens AFM, van Baalen 
384

385

386

387

388

389

390

391

392

393

394

395

396

397

398

399

400

401

402

403

404

405

406

407

408

409

410

411

412

413

T et al. The degree of whey hydrolysis does not uniformly affect in vitro basophil and T cell responses of cow's milk-allergic patients. Clin Exp Allergy 2014;44:529-539.

13. Nurmatov $U$, Dhami S, Arasi S, Pajno GB, Fernandez-Rivas M, Muraro A et al. Allergen immunotherapy for IgE-mediated food allergy: a systematic review and meta-analysis. Allergy Published Online First: 11 May 2017. doi:10.1111/all.13124

14. Larsen JM, Bøgh KL. Animal models of allergen-specific immunotherapy in food allergy: Overview and opportunities. Clin Exp Allergy Published Online First: 16 July 2018. doi:10.1111/cea.13212

15. Holt PG, Turner KJ. Persistent IgE-secreting cells which are refractory to T-cell control. Int Arch Allergy Appl Immunol 1985;77:45-46.

16. Madsen J, Kroghsbo S, Madsen C, Pozdnyakova I, Barkholt V, Bøgh K. The impact of structural integrity and route of administration on the antibody specificity against three cow's milk allergens - a study in Brown Norway rats. Clin Transl Allergy 2014;4:25.

17. Ladics GS, Fry J, Goodman R, Herouet-Guicheney C, Hoffmann-Sommergruber K, Madsen CB et al. Allergic sensitization: screening methods. Clin Transl Allergy 2014;4:13.

18. $\mathrm{B} \emptyset \mathrm{gh} \mathrm{KL}$, Barkholt V, Madsen CB. Characterization of the Immunogenicity and Allergenicity of Two Cow's Milk Hydrolysates - A Study in Brown Norway Rats. Scand J Immunol 2015;81:274-283.

19. Burton OT, Tamayo JM, Stranks AJ, Koleoglou KJ, Oettgen HC. Allergen-specific IgG antibody signaling through FcyRIlb promotes food tolerance. J Allergy Clin Immunol 2018;141:189201.e3.

20. Meulenbroek LAPM, van Esch BCAM, Hofman GA, den Hartog Jager CF, Nauta AJ, Willemsen LEM et al. Oral treatment with $\beta$-lactoglobulin peptides prevents clinical symptoms in a mouse model for cow's milk allergy. Pediatr Allergy Immunol 2013;24:656-664.

21. Lindholm Bøgh K, Barkholt V, Bernhard Madsen C. The Sensitising Capacity of Intact Lactoglobulin Is Reduced by Co-Administration with Digested $>$-Lactoglobulin. Int Arch Allergy Immunol 2013;161:21-36.

22. Kulis M, Macqueen I, Li Y, Guo R, Zhong X-P, Burks AW. Pepsinized cashew proteins are hypoallergenic and immunogenic and provide effective immunotherapy in mice with cashew allergy. J Allergy Clin Immunol 2012;130:716-723. 
414

415

416

417

418

419

420

421

422

423

424

425

426

427

428

429

430

431

432

433

23. Yang M, Yang C, Nau F, Pasco M, Juneja LR, Okubo T et al. Immunomodulatory effects of egg white enzymatic hydrolysates containing immunodominant epitopes in a BALB/C mouse model of egg allergy. J Agric Food Chem 2009;57:2241-2248.

24. Yang M, Yang C, Mine Y. Multiple T cell epitope peptides suppress allergic responses in an egg allergy mouse model by the elicitation of forkhead box transcription factor 3- and transforming growth factor- $\beta$-associated mechanisms. Clin Exp Allergy 2010;40:668-678.

25. Rupa P, Mine Y. Oral immunotherapy with immunodominant T-cell epitope peptides alleviates allergic reactions in a Balb/c mouse model of egg allergy. Allergy 2012;67:74-82.

26. Wai CYY, Leung NYH, Leung PSC, Chu KH. T cell epitope immunotherapy ameliorates allergic responses in a murine model of shrimp allergy. Clin Exp Allergy 2016;46:491-503.

27. Thang $\mathrm{CL}$, Zhao X. Effects of orally administered immunodominant T-cell epitope peptides on cow's milk protein allergy in a mouse model. Food Res Int 2015;71:126-131.

28. Du Toit G, Roberts G, Sayre PH, Bahnson HT, Radulovic S, Santos AF et al. Randomized Trial of Peanut Consumption in Infants at Risk for Peanut Allergy. N Engl J Med 2015;372:803813.

29. Vandenplas Y, Latiff AHA, Fleischer DM, Gutiérrez-Castrellón P, Miqdady M-IS, Smith PK et al. Partially hydrolyzed formula in non-exclusively breastfed infants: A systematic review and expert consensus. Nutrition 2019;57:268-274. 


\section{FIGURE 1}

A

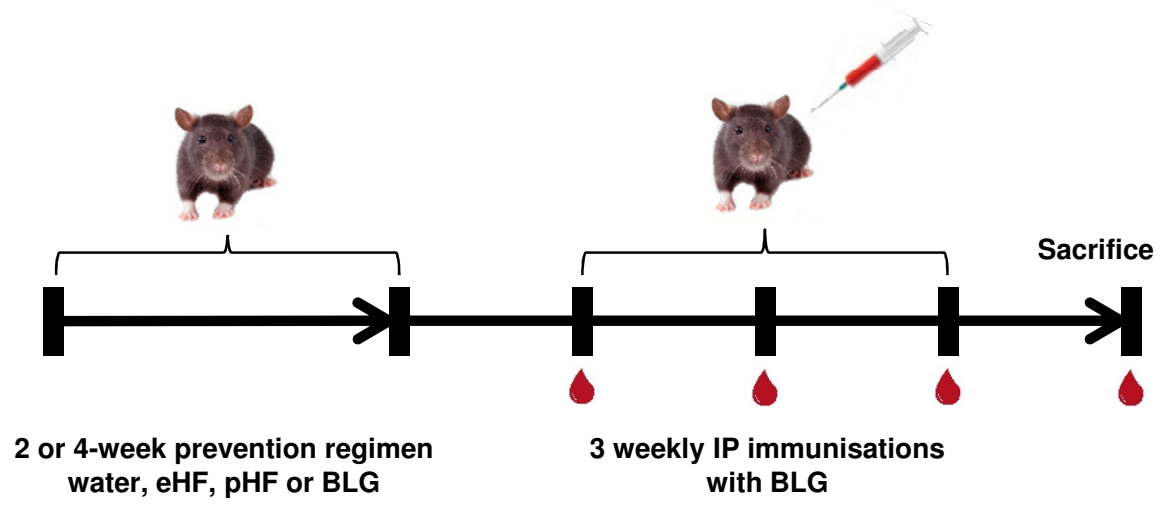

B
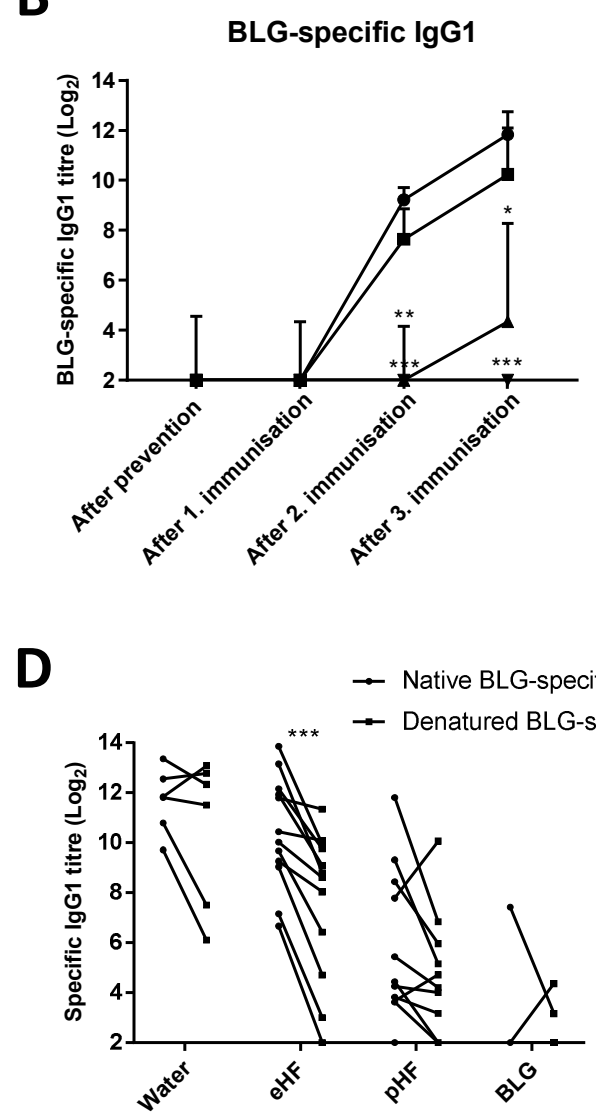

Prevention regimen
C

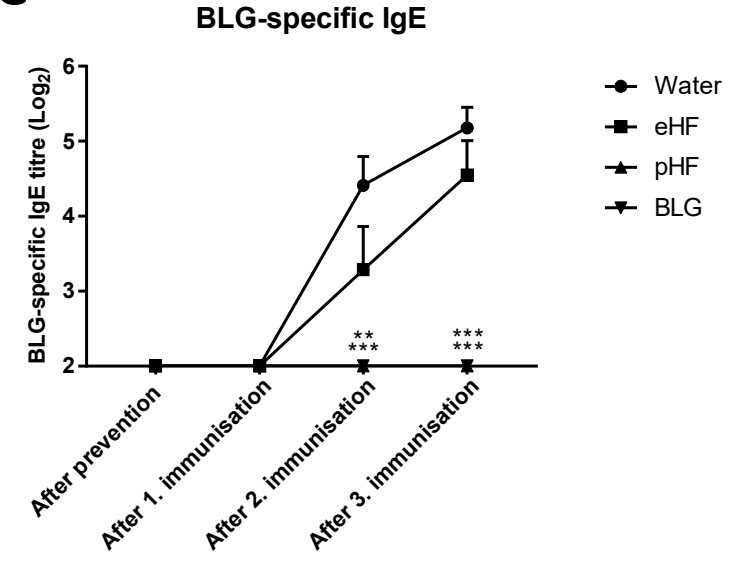

E

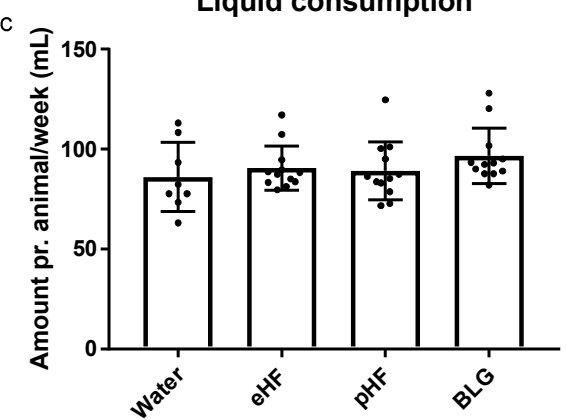

Prevention regimen 


\section{FIGURE 2}

A

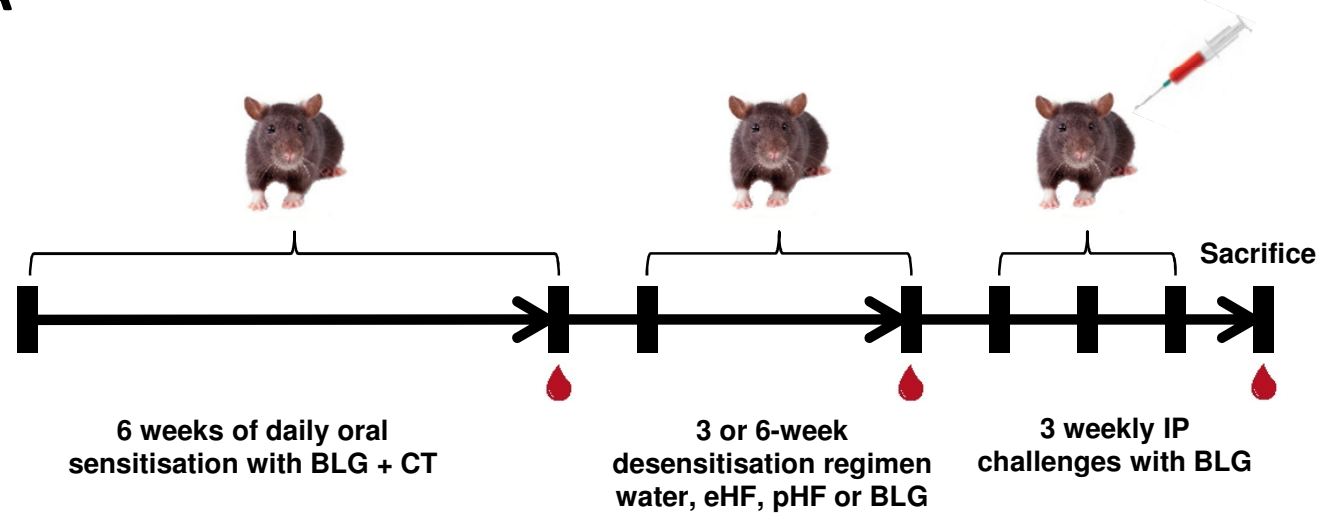

B

Before vs. after desensitisation

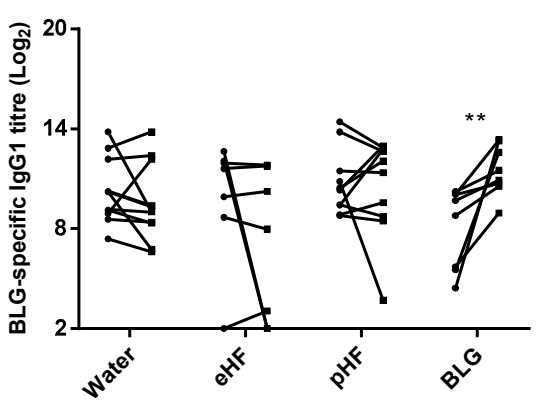

D

Desensitisation regimen

Before vs. after challenge

E

C Before vs. after desensitisation

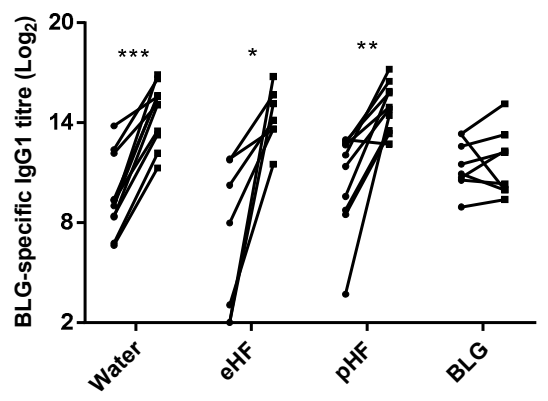

Desensitisation regimen

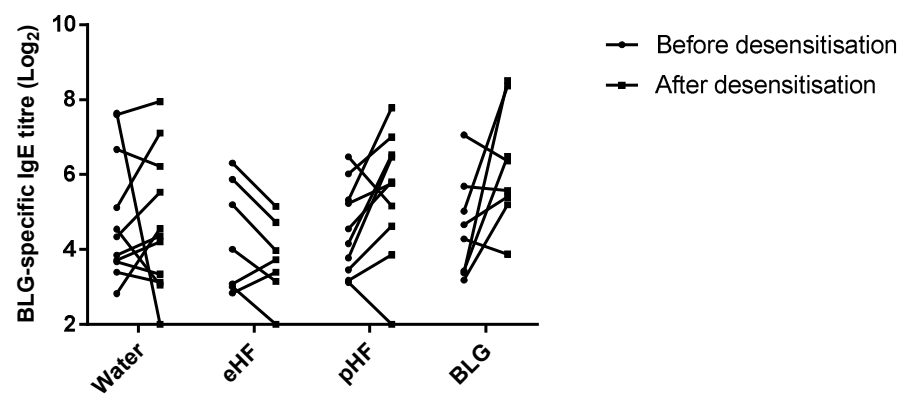

Desensitisation regimen

Before vs. after challenge

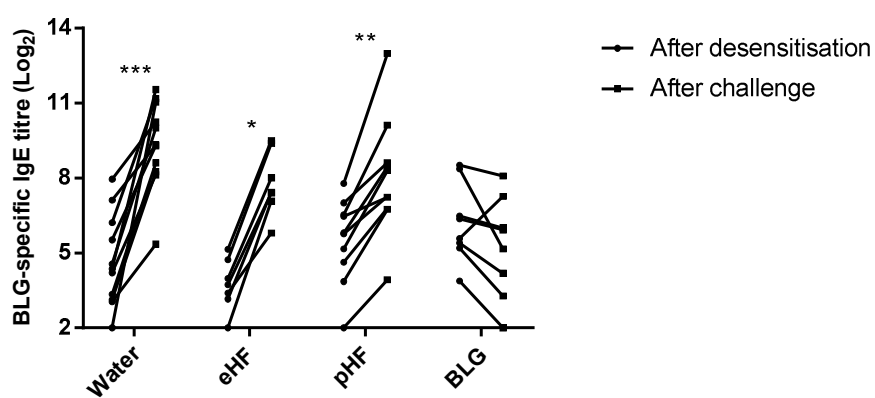

$\mathbf{F}$

$\mathbf{G}$

Desensitisation regimen

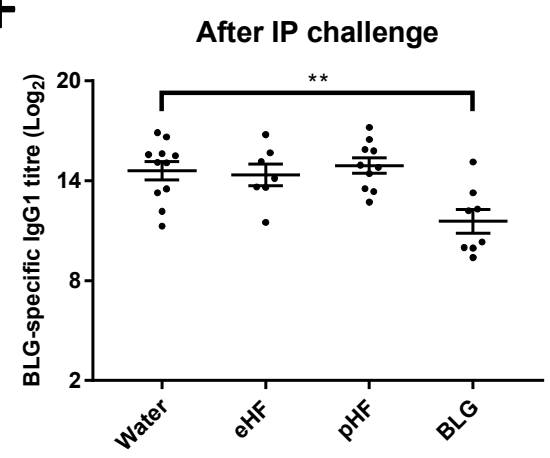

Desensitisation regimen

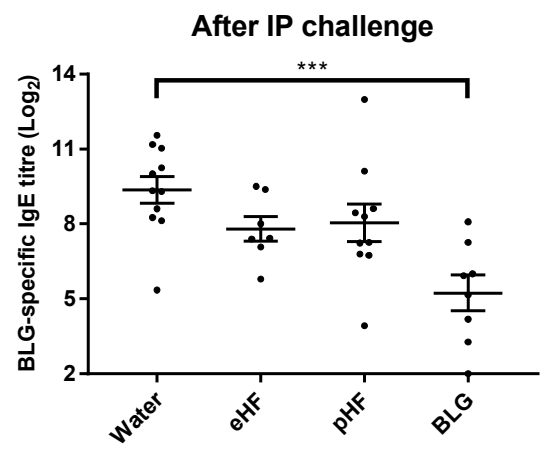

Desensitisation regimen 